\title{
Analysis of English and American Literature Teaching in Perspective of Cognitive Poetics
}

\author{
Yan Li \\ School of foreign language and literature, Wuhan Donghu University, Wuhan Hubei, 430212, China
}

Keywords: Cognitive poetics, English and American literature, Classroom teaching.

\begin{abstract}
The new era, new curriculum reform of university has been gradually deepening and development, strengthen the quality of English and American literature education to some extent, promote the use of traditional modes of teaching suffer serious adverse effects. Thus it is necessary to combine students' daily cognitive ability and ability to accept literature make recommendations for the effective implementation of the teaching of English and American Literature, American Literature Teaching Chinese universities to promote better development.
\end{abstract}

\section{Introduction}

As we all know, with the influence of economic globalization on countries increasingly strengthened, showing the world's cultural integration of the development trend, the Anglo-American literature has become the focus of professional courses in English, to cultivate and strengthen the ability of the English translation of Humanities Quality produce certain impact, but also the main focus of higher education reform. But from the current situation in Literature Teaching current development of China, the cultivation of students whose English literature quality is far unable to meet the market economy requirements for the quality of talent, cannot play a relevant role in promoting the overall development of students. The cognitive poetics is a more emphasis on academic theory of literature text analysis and interpretation of cognitive poetics as the theoretical basis for Literature Teaching make the appropriate guidance, can promote students' understanding and knowledge of English literature application corresponding increase capacity, and promoting the overall development of students, it can give full play to educate and guide the cognitive function of poetry in English teaching, the teaching of English and American literature appropriate reforms and innovation, deepen the development of English and American Literature Teaching provided appropriate protection.

\section{Basic connotation and literature function of cognitive poetics}

\section{Basic connotation of cognitive poetics}

Late last century, literature began to emerge sprout cognitive poetics, for some researchers began to study the problem of cognitive poetics, and ultimately be defined as emerging discipline of English education. Although this subject has been attributed to the English education, but its development has also experienced a more complex changes, ideological content are constantly being adjusted and optimized, mainly contains three important stages: First, the researcher Tsur clear in the analysis pointed out that this literary poetry from life in general, poetry inherent in thought and meaning to people's lives can actually achieve a certain unity, so the study formally proposed the concept of cognitive poetics, hope that through rational exploration, gradually found in poetry problems and the impact of different issues of human cognitive activities and the like. Second, in the study of cognitive poetics concept is presented and a certain development, the researchers in the study of practice which began to try to combine analysis and linguistics, hopes to tap into a large number of cognitive linguistics theories language Features text analysis, the study of cognitive poetics be enriched and improved comprehensive theory [1]. Third, in the theory of cognitive poetics obtain the corresponding rich, and researchers in the study of linguistics and cognitive psychology comprehensive, appreciation of British and American literature to explore. During this phase focused 
on the British and American Literature reading it should be noted that in the ground, in a certain emotional resonance with the author and the hero, prompting the reader the ability to interact and literary language skills can get the corresponding text itself strengthened. All in all, the study of cognitive poetics is combined with previous results of exploration and discovery, combined view of the new era emerged, with interpretation of British and American Literature to be rich in its theory, and the theory counterproductive in English and American literature, British and American Literature Teaching practice provides guidance.

\section{Literature function of cognitive poetics}

rom the above analysis we can see cognitive poetics from the nature point of view is a new kind of literary theory will be applied to the analysis of literary works can achieve higher performance, the angle and literary analysis of more innovative content to enrich . In cognitive poetics, the authors show how the appropriate thoughts and feelings in the works, the reader how to get by reading the corresponding emotional experience in-depth analysis. With researchers associated cognitive poetic theory more in-depth research, personal knowledge between the universality of public awareness and access to the appropriate balance under the influence of this theory, cognitive poetics Research in the field has been further expanded, research from the perspective of the traditional poetic analysis to explore the development of cultural and social context, meaning creation from research literature gradually transformed into the reader in the reading process to build on the literary content [2]. To today's society, the field of cognitive poetics has been gradually extended to the aesthetic connotation of literary works in-depth analysis to guide the reader to complete the literary works of sentimental value realized in the reading process, and then build the reader's own inner world and strengthen cognitive emotion corresponding impact. Therefore we can say, from the study of cognitive poetics of

English and American Literature, British and American Literature Teaching Reform to make the appropriate guide has some practical significance.

\section{Status of English and American literature teaching in Chinese college}

Teaching English Literature in Chinese universities, the main objective of teaching is to cultivate students' professional knowledge and skills, and professional students the knowledge and skills they will inevitably involve a certain language and culture and literary content, in college English major courses settings, and American literature has always been required courses by university teachers and students attention. But be from the current actual situation of teaching English and American literature analysis, by the influence of traditional teaching philosophy, curriculum teaching system flawed, is not conducive to further enhance the quality of teaching.

First: The current British and American Literature Teaching China's general lack of clear teaching objectives. In accordance with the relevant requirements of the new curriculum standards, carry out literature courses must take up the students literary works enjoy reading ability, enhance responsibility works appreciation, and attention to strengthening students' cultural literacy and English language proficiency, students by the Anglo-American Literature study, not only to broaden their horizons, of Western culture have a deeper understanding, you can also enhance the overall quality of students, for students to get better development lay the foundation for the future. But from the actual teaching situation in colleges and universities and American literature of our country, the teachers' explanation mainly requires students to the history of literature recite as the main content, literature courses function in personnel training cannot be fully exploited, the students even received the corresponding literary education, it will not read a lot of classics, the natural effect of teaching cannot be fully exploited, the culture of the humanities going.

Secondly, universities and American literature teaching hours set a serious shortage, unable to meet the learning needs of students. Affected by the negative effects of the current market economy, social utilitarian tendency even more serious literature courses gradually showing a marginal trend, adversely affecting the British and American Literature Teaching in Universities. Where class is insufficient to limit the effect of teaching, English and American literature gives one of the most 
important reasons for the improved accordingly. Currently in English and American literature teaching, teachers are generally difficult to guide students to read a large number of British and American literature classics in a limited time, and less likely to work with students in-depth research and analysis, and even some English in College Applications smaller specialty in English and American literature just one elective course, not only ignored, but also a serious shortage of teaching hours, severely restricted the play teaching effect, cannot even meet the learning needs of students.

Finally, the teaching method is relatively inflexible. As part of the school curriculum is the lack of English and American Literature enough attention in the course curriculum, resulting in the classroom is often the teacher to explain and be unilateral interpretation of the text, and students passive acceptance of knowledge, not only cannot effectively stimulate students enthusiasm for learning, is not conducive to students' interest in learning and literature literary literacy [3]. Over time, British and American literature courses gradually lost its advantage in terms of students' comprehensive ability, marginalization trends become more apparent. Therefore, in order to fully highlight the characteristics of teaching English and American literature, to promote the teaching of English and American Literature function can be fully exploited, is necessary to combine scientific knowledge Poetic Thought teaching reform, promote the development of English and American Literature to get better in the future.

\section{Measures to optimize English and American teaching from perspective of cognitive poetics}

\section{Emphasis on rationality and applicability of materials in the process of textbook compilation}

Cognitive poetic theory for the development of English and American literature teaching reform has opened up new roads, in teaching practice reform, in order to ensure that the important role of literary theory can be brought into full play, the teacher should first textbook from prepared to start, to take appropriate measures to gradually enhance the rationality and applicability textbook work. British and American Literature Teaching in China College currently used materials, the general in order to compile manner chronological-based, and each part of the design model is more fixed, mainly for the "Backgrounder, writers' growth process, typical chapter excerpts, comments." This preparation of form led to the students in the learning process first exposed to the history of literature related information, cannot stimulate students 'interest in learning, and into specific sections later analysis, or even a part of student teaching boredom and psychological conflict, serious impact on students' learning enthusiasm, It is not conducive to students learning English and American Literature systems. In response to this situation, the process of teachers in English and American literature written in textbooks should be noted that appropriate reform and innovation, appropriate to set some literary works have a certain appeal in the circumstances in each chapter the forefront to ensure that teaching can effectively stimulate student interest and allow students to leave the initial impression of literary works, provide back-up to the effective classroom teaching, prompting the British and American Literature Teaching effectiveness corresponding increase.

\section{Continue to adjust teaching organization way}

Reform in the teaching process in the preparation of teaching materials once adjusted accordingly, teaching organization will also inevitably produce a corresponding change. In Cognitive Poetic Perspective on Literature Teaching reform must be students as the main body, so based on the compilation of teaching materials in the form of adjustments to the British and American Literature Course organization should also pay attention to optimize the dominant position of students. In today's society the Internet and computer technology is increasingly widely used in education background, teachers on British and American literature courses also can make use of more advanced multimedia teaching equipment, modern teaching methods to provide students with relevant literature, pictures and videos on the basis of full stimulate students interest in learning, the student's point of view from the start of scientific teaching organization, to meet the needs of students but also to promote the teaching effect can be a corresponding increase [4]. As a specific process of teaching, 
teachers in British and American literature relevant content to explain from human feelings angle start guide students germinal corresponding emotion in the text reading process, thereby generating the author and cultural heroes in emotional resonance, and thus to content of the work, etc. to form a more profound understanding, achieve better teaching results.

\section{Enrich teaching evaluation method}

Based on the organizational form of teaching to make reasonable adjustments to enhance the applicability of the organization should also be combined teaching on the teaching needs of the teaching evaluation methods and evaluation criteria for a new exploration. Scientific and reasonable teaching evaluation of students' passion can play a good role in excitation, on the contrary, if the teachers unreasonable evaluation methods, evaluation or teaching standards in the teaching process, the lack of subjectivity, it is not only unable to find Literature Teaching effect has been optimized to adjust, or even discourage students' enthusiasm is not conducive to enhancing the quality of teaching of English and American Literature. Traditional Literature Teaching Evaluation System in China has a certain mechanical resistance, cannot for the learning ability among students, individual differences in terms of learning outcomes for students to implement targeted assessment is likely to dampen the students' self-esteem and self-confidence of students and American Literature literacy Training adverse effects [5]. Therefore, in the perspective of cognitive science poetry, teachers can be combined with the actual situation of the students have the appropriate evaluation criteria targeted to develop, evaluate and set up a wide range of measures, such as teacher evaluation and student peer assessment, qualitative and quantitative evaluation of combining, process evaluation and outcome evaluation by combining dynamic evaluation and static evaluation of the combination, to enhance the scientific and effective evaluation, encourage students to get some incentives and encouragement in the evaluation of teaching quality for students learning English and American Literature enhance the effect of the foundation.

\section{Conclusions}

In summary, the time of occurrence of cognitive poetics of late, which is only gradually emerging discipline and get some development in the last 20 years, although from research and development to see still in its infancy, but one has thought about teaching of literature can produce a corresponding revelation. Cognitive Poetic Perspective be studied English and American literature teaching, it is to make use of cognitive things British and American literature aesthetic model cognitive model for analysis, to provide appropriate guidance for the current teaching of English and American Literature. Overall Cognitive Perspective is in poetry, English and American literature textbook compilation, as well as to adjust the way of teaching evaluation of teaching organizational forms should be accepted on cognitive poetics of teaching philosophy, to enhance the teaching of science, so that students can in the process of learning to cognitive literary transition from everyday cognition, on the basis of enhancing the effectiveness of the teaching, also contributed to the students' ability aesthetic and literary accomplishment corresponding reinforcement, lay a solid foundation for their future better development.

\section{References}

[1] Shi Min. English and American Literature Teaching under Cognitive Poetic Perspective, GuangDong Polytechnic Normal University(Social Science Edition),2012(5):108-109.

[2] Hou Xia. English and American Literature Teaching based on Cognitive Poetic, Journal of Hubei Correspondence University,2015(3):117-118.

[3] Xu Xiaoli. English and American Literature Teaching under Cognitive Poetic Horizon, Jiannan Litrature,2013(5):386-386. 
[4] Mao Yanhua. English and American Literature Teaching under Cognitive Poetic vision, Zhejiang Wanli College Journal,2013,26(5):105-108.

[5] Lin Jiuju. Significance of cognitive poetic in English and American Literature teaching, Science guidance,2014(9):243-243. 